Re-using the Names of Newborns: Symbolic Reincarnation in an Age of Infant Mortality

Stephen J. Bush

ORCID: $\quad$ 0000-0001-9341-2562 


\title{
Re-using the Names of Newborns: Symbolic Reincarnation in an Age of Infant Mortality
}

\begin{abstract}
The naming of a newborn for a deceased relative is a means by which a meaningful connection can be maintained with the dead. This study analyses the birth, marriage and death records of England and Wales to highlight a historic naming custom - that should a child die shortly after birth, their name could often be re-used for a later sibling.

This re-use of names in response to child bereavement is considered in the context of historic and cross-cultural naming customs offering pragmatic responses to infant mortality, such as apotropaic (protective) naming, and within the theoretical framework of 'continuing bonds', whereby namesakes can facilitate a post-mortem social life for the deceased. By considering the intricate relationship between one's name and one's personhood, the re-use of a name in full, shortly after death, could be interpreted as the symbolic reincarnation of an individual, rather than simply as a commemorative act.
\end{abstract}

Keywords: commemorative naming, apotropaic names, continuing bonds, infant mortality, bereavement, personhood, England, Wales, UK 


\section{Introduction}

Personal names may be given in response to, and transcendence of, death. For instance, in the Ashkenazi Jewish tradition, naming a newborn after a deceased relative emphasises intergenerational continuity within the family unit, with the child a 'living monument' to family memory (Mendels 2007). Similarly, in the Inuit tradition, commemorative naming honours the deceased namesake, with the shared name not only symbolic of shared identity (Alia 2009) but reportedly having lifelong impact on how the child is regarded - a boy named for his deceased maternal grandmother can be addressed by his mother as 'mother' and dressed in female clothing (Seeman 1983, Guemple 1965). That in this case the symbolic is also literal has been summarised as 'in a sense, names are dead people in Inuit ideology' (Macdonald 2009). Neither custom is conceptually dissimilar from papponymic naming traditions, such as those documented among Sephardic Jews (Samuel 1969) - the naming of children for their grandparents, who, even if alive at the time of the child's naming, are likely to pre-decease the child. In some societies, the naming of children for grandparents may have literal rather than symbolic meaning. For instance, names in use among the Yoruba (West Africa) make explicit reference to a belief in familial reincarnation, such as Babatunde ('the father has returned') and Yetunde or Iyabode ('the mother has returned') (Okehie-Offoha and Sadiku 1995). These names may be given, respectively, to males born after their grandfather has died, and females born after their grandmother has died.

In general, this suggests that commemorative naming is (or has been) a means by which a meaningful connection can be maintained with the deceased. Through one's namesake, who acts implicitly as spur to family memory, the absent dead remain symbolically present - and their contribution to social life extends, by proxy, beyond their physical life. 
To theorise the intricate relationships between the living and the dead, and to critique the dominant (Western) model of grief at the time - which encouraged 'decathecting', the withdrawal of emotional energy from the dead - Klass et al. coined the term 'continuing bonds' in 1996 (Nickman 1996). While continuing bonds are commonly understood to mean the presence of an ongoing inner relationship with the deceased by the bereaved, it is far from clear as to whether retaining or relinquishing these bonds is, in general, helpful (Stroebe and Schut 2005).

This study focuses on the onomastic, rather than sociological, character of such a bond. By analysing registers of births, marriages and deaths, this study identifies naming patterns supportive of relationships with the dead (irrespective of any adaptive or maladaptive value for these relationships) within England and Wales. Numerous means by which continuing bonds facilitate post-mortem social life (that is, 'intensify the presence of the deceased' (Jonsson 2015)) are discussed in (Root and Exline 2014), and can manifest both tangibly (such as via relics (McCormick 2015) and visiting memorials, both online (Irwin 2015) and in person (Toplean 2015)) and intangibly (by doing things the deceased would have liked (Foster et al. 2011), internalizing their beliefs (Klass 1993), or by incorporating their ambitions into everyday life (Vickio 1999)). It is reasonable to believe that naming a newborn for the dead can act in much the same manner - a namesake intensifies the presence of the deceased by being an explicit everyday reference to them, one that is in essence permanent for the length of an additional lifetime.

While this provides a theoretical basis for the motivation underlying namesakes, it is unclear how widespread this practice is. Many accounts of commemorative naming have focused on the naming of newborns for deceased adult relatives, often grandparents. A comparatively little-explored aspect of commemorative naming customs is the naming of a newborn for a deceased child relative, often a sibling. 
In England and Wales, birth, marriage and death records span from the $19^{\text {th }}$ century to the present day, and so provide extensive coverage of a historical period in which infant mortality was commonplace. By cross-referencing these records, it is possible to associate deaths in infancy with individuals born at a later date to the same parents. Using conservative criteria to ensure that family relationships were accurately reconstructed, an initial dataset of approximately 23 million birth records, 19 million marriage records and 13 million death records was filtered to obtain approximately 9000 death records at $<1$ year of age, to which one or more birth records for a sibling could be associated.

By analysing this subset of death record/birth record pairs, this study identifies a prevalent naming phenomenon - that should a child die in infancy, it was reasonably common practice to re-use their full name (that is, first name and all middle names) for that of a sibling. This applied equally both to male and female births. In $10 \%$ of birth records linked to a previous death, the full name of the deceased was re-used for the newborn; in another $11 \%$ of records, only the first name was re-used. Less frequently, the first name of the deceased was used as the middle name of a newborn in approximately $4 \%$ of cases.

The re-use of names in response to child bereavement is discussed within the context of continuing bonds, as the symbolic reincarnation of the dead in the form of their sibling, and as a pragmatic custom in an age of high infant mortality.

\section{Materials and methods}

\section{Cross-referencing birth, marriage and death records to identify deaths in infancy and}

\section{associated siblings}

Birth, marriage and death (BMD) records - which began in England and Wales in 1837 were obtained from the UK 'local BMD' project (http://www.ukbmd.org.uk/local), a 
volunteer effort to transcribe the local indices of the UK BMD registers for digital preservation (these local indices were originally sent, each quarter, to a central body, the General Register Office in London, to be compiled into a national catalogue; this catalogue is not publicly available). BMD records were collated from all participating areas in the UK local BMD project on $29^{\text {th }}$ January 2018 - the cities, counties and regions of Bath, Berkshire, Cheshire, Cumbria, Lancashire, North Wales, Staffordshire, West Midlands, Wiltshire, and Yorkshire (hereafter, these will all be referred to as 'regions'). Each of these areas constitutes a different volunteer-led record transcription project, although several (Berkshire, Cumbria, North Wales) have not been actively maintained, having no new records for $4-5$ years prior to data collation. Typographical errors were corrected and uninformative entries (such as names registered with a single initial, or generic placeholders such as Boy and Girl) excluded. These corrections are detailed alongside a corpus of names derived from the birth records, hosted via the University of Edinburgh DataShare portal (http://dx.doi.org/10.7488/ds/2294) and made available as part of a separate study applying network analysis methods to onomastic data (Bush, Powell-Smith, and Freeman 2018).

In total, $23,468,892$ birth records, $18,864,672$ marriage records and 13,379,636 death records were examined for this study (the number of records per region, and the years and regions covered, are detailed in (Bush, Powell-Smith, and Freeman 2018)). The available fields for each person's birth record were the first name, middle name(s) and surname, mother's maiden name (where applicable), year of birth, sub-district of the region in which the birth was registered, and identification number. For death records, available fields were the first name, middle name(s) and surname, age at death (where known), year of death, sub-district of the region in which the death was registered, and identification number. Age at death is not provided for records in the regions of Cumbria, North Wales and the West Midlands. Uniquely, records from the Staffordshire region list either age at death, or - in the same field 
- the date of death, if known. For marriage records, available fields were the first names, middle name(s) and surnames of both parties, year of marriage, the venue (typically, a church or registry office) in which the marriage was registered, and identification number.

For all three record types, identification numbers are unique: one per birth, death and marriage. However, multiple marriage records may share the same identification number - if one member of a couple has had a previous surname, a parallel record is created for the former name also (for instance, if $\mathrm{X}$ marries $\mathrm{Y}$ but was previously married to $\mathrm{Z}$, there will be duplicate marriage records: of $\mathrm{X}$ with $\mathrm{Y}$, and $\mathrm{X}$ with $\mathrm{Z}$ ).

To identify individuals who died in infancy, identical names were required on birth and death records from the same year, both registered in the same sub-district of the same region, and with the age of death recorded as ' 0 ' (i.e., $<1$ year). Records were required to be unique: only one birth and one death record of that name per sub-district per year. Infant mortality rates were far higher historically, but the diversity of forenames was far lower. As such, to reduce ambiguity (given there would be a larger number of similarly-named records), we also required both birth and death record to have the same middle name(s). The stringency of these criteria unavoidably excludes records because (a) in conjunction with historically lower forename diversity, fewer individuals used middle names (by 1800, only $10 \%$ of the English population had a middle name (Mitterauer 1993)), (b) multiple births and deaths would be expected for common surnames (such as Smith), reducing the number of unique names found per sub-district per year, and (c) birth and death records are required to be in the same year, but a death aged '0' could transcend a year boundary (for example, a birth in December, but death in January).

As the majority of records are historical, we could reasonably assume a traditional marital practice of the time: that the mother would be married prior to giving birth, and that the birth would be registered with the surname of the father (while this practice is less common in 
contemporary records, so too is infant mortality). Accordingly, for each birth/death, a unique marriage record was required predating the birth/death by no greater than 10 years, i.e. that there was only one record within that period containing the surnames of both parents. Marriage records were required within the same region as the birth and death records (e.g. 'Bath') but not necessarily the same sub-district (e.g. 'Bath North'). This is because the marriage records contain, rather than the name of the sub-district, the name of the specific church or registry office within that sub-district. The mother's maiden name, obtained from the birth record, was cross-referenced with the two surnames listed on the marriage record. A match was required to one of these two surnames, with the two surnames required to be different. To confirm this was the mother's maiden name, the gender of the forename associated with this surname was required to be female (see below). A similar match was required of the second surname: that it matches the surname of the deceased, and that its associated forename is male.

Overall, these conservative criteria allow the reasonable identification of family relationships from the data - in particular, siblings born after the death of the newborn. As the aim of this study is to determine whether, and to what extent, the names of the deceased may be re-used as the names of siblings, only the records of same-sex siblings are considered. From the total number of age 0 death records $(n=1,607,596)$, a subset of 51,476 death record/birth record pairings could be made - that is, one death record associated both with one or more birth records for a probable same-sex sibling (in the same sub-district, with a middle name, with the same gender for the first name, and with birth and death record unique in that sub-district in that year) and a unique candidate marriage record (registered up to 10 years before birth, and with the surname of the deceased [on the birth and death records] matching the male name on the marriage record, and the mother's maiden name [on the birth record] matching 
the female name on the marriage record). This subset of paired death/birth records are referred to as 'usable death records' and are the basis of all subsequent analysis.

\section{Inferring gender from birth records}

The 'UK local BMD' birth records omit the sex assigned to each individual. Although the gender of each name can be predicted, this is not trivial: many names are unisex (although, like Leslie and Robin, more likely to be female (Lieberson, Dumais, and Baumann 2000)) and many records are ambiguous in the absence of contextual information (for instance, knowing only the forename, Jan may be an English female or Dutch male name). For this study, gender is predicted by reference to census data from the United States, as in (West et al. 2013). This census data is a corpus of first names, and an associated gender, collated by the United States Social Security Administration in the period 1880 to 2015 (https://www.ssa.gov/OACT/babynames/names.zip; accessed 15th November 2016). We assume the gender of a name if it can be assigned to a single gender in $>95 \%$ of cases. Note that this dataset acknowledges only two genders.

\section{Data usage statement}

The website hosting the UK local BMD project, www.ukbmd.org.uk, is operated by Weston Technologies Ltd (Crewe, Cheshire, UK). This company is the owner or license-holder of the intellectual property constituting the birth, marriage and death records - obtained from the subsidiary websites listed in (Bush, Powell-Smith, and Freeman 2018) - as detailed at https://www.ukbmd.org.uk/TermsAndConditions (accessed 29th January 2018). Under section 29A of the UK Copyright, Designs and Patents Act 1988, a copyright exception permits copies to be made of lawfully accessible material in order to conduct text and data mining for non-commercial research. This exception is invoked here. 


\section{Results}

\section{The names of deceased infants have often been re-used in England and Wales as the}

names of their siblings

Infant mortality (here limited to deaths at $<1$ year of age) was historically extensive, with the vast majority of infant death records (70\%) registered prior to 1900 (Figure 1).

\section{<place Figure 1 here $>$}

This substantial reduction in infant mortality can be associated with turn-of-the-century investment in public health infrastructure (Bell and Millward 1998), and improved cleaning of the market milk supply (Lee 2007) (milk being the transmission vector for bovine tuberculosis, one of the leading causes of death in the $19^{\text {th }}$ century (Atkins 1999)). By cross-referencing regional birth, marriage and death records from England and Wales, a conservative subset of infant death records was obtained for more detailed analysis. These records allow the reasonable inference of family relationships from the data, so that each death record can be paired with the birth records of one or more siblings. Of the total number of death records in the dataset $(n=13,379,636), 12 \%$ are registered at $<1$ year of age $(n=$ 1,607,596). From this subset, 51,476 pairings could be made between the death records and the birth records of one or more siblings. As one death record can be paired with multiple birth records (that is, multiple possible siblings), the total set of pairings represents 9452 individual deaths.

Of the 9452 individual death records, 947 (10\%) could be linked to a birth record of the same full name - that is, to a sibling named identically to the deceased (Table 1).

\section{<place Table1 here>}


Furthermore, 1975 births (21\%) have the same first name as the deceased - that is, for 947 births, both the forename and middle name have been reused from the deceased, and for 1028 births, only the former. The re-use of a full name is irrespective of gender: approximately as many male names (49\%; 466 of 947 names) are re-used as female (51\%; 481 names). These proportions reflect the lack of bias in birth: of the 9452 death records with an associated sibling, 5002 (53\%) have male names and 4450 (47\%) female names.

While the re-use of a full name is largely restricted to $19^{\text {th }}$ century records and for the most part disappears due to advances in healthcare, it can still be found in a limited number of $20^{\text {th }}$ century records, with the three most recent death record/birth record pairs found for deaths in 1968, 1969, and 1978. Of the 947 instances of name re-use, only 42 are found in the last 100 years.

For the set of identically named records, the time between the death and the subsequent birth of the sibling is relatively short: on average, 2.8 years (this is inevitably an overestimate as the records provide only year of birth, not month). As a consequence, there are several examples of parents giving the same name to a child, after successive deaths in infancy. For instance, the names John Whitehead Taylor are registered to the same parents in the same district in 1839, 1842 and 1845, as are George Edward Dodd for births in 1858, 1859 and 1861. There are also occasions where this approach is abandoned. The birth and death of Thomas Henthorn Travis in 1840 was followed, in 1841, by the birth and death of his namesake. However, after the 1841 death, a subsequent sibling, born in 1842, was named William Henthorn Travis.

These results suggest that name re-use was a relatively common practice in response to child bereavement. The necessity of a conservative approach to identifying pairs of death and birth records - in particular, requiring a middle name at a time when they were comparatively uncommon - likely underestimates the extent of this custom. 


\section{Discussion}

Although grief is private in nature, the results of this study suggest a repeatedly occurring similarity among the population of England and Wales - at least historically - in response to child bereavement. A substantial proportion of families can be seen to re-use, in full or in part, the name of a deceased newborn as the name of a sibling. Writing from the perspective of a time and place in which healthcare advances ensure infant mortality is much rarer, it is not only hard to fathom so commonplace a reason for grief but the nature of the response to it - that is, the subjective meaning assigned by the parents to the decision to re-use a name, to ascribe to a child (born on average less than 3 years after the death of their sibling) an identical signifier. Accordingly, this custom will be largely discussed in the context of other naming conventions related to infant mortality.

Acknowledging infant mortality as both universal and (historically more) common, numerous naming customs appear pragmatic in response. In many societies, children may be named in a way to safeguard from harm. Assuming illness or death to arise by the action of malevolent spirits, males in India have reportedly been given the apotropaic (protective) name Kuriya ('dunghill') because 'the spirit of course knows folk as their names and will overlook the worthless' (Ogden and Richards 1946) - the demeaning name is a protective deception. A similar custom has been documented in Roman Egypt, through derogative names such as Kopreias, Koprias and Kopreas, all deriving from kopreus ('dung') (Dasen 2011), and among the Hausa (West Africa), through names such as Kandi (from kandilu, 'cow dung') and Tanko (from tankoshe, 'repelled') (Tremearne 2014). Throughout the Middle East, the names of animals can have both metaphoric and apotropaic aspects, being imbued either with negative connotations ( so a child named for an 'unclean' animal would be unattractive to evil 
spirits) or powerful ones, presenting a threat (so a child named for a dangerous animal could fight off malign influence) (Dirbas 2017).

With advances in healthcare and education, it is reasonable to believe derogative apotropaic names - chosen for their utility, rather than cultural, aesthetic or honorific reasons - will disappear from contemporary records. In many historic accounts, apotropaic naming customs are often described anecdotally, and so it is unknown how prevalent such names actually are. For instance, a particularly detailed description of apotropaic naming is given by the soldier and ethnographer A. J. N. Tremearne in a 1914 account of his time among the Hausa (Tremearne 1914):

When a mother has had several children who have died young, special care will be taken with the next, for it is recognised that the woman is a wabi-i.e. one fated to lose her offspring. One way is as follows. It [the child] is taken upon a cloth by the mother and placed disdainfully upon a dung-hill, or upon a heap of dust, and left there by her, she going home and pretending to abandon it. But immediately behind her come friends, who pick it up, and take it back to her. The child will have only one half of its head shaved alternately until adult, and will be called Ajuji (Upon the Dunghill) or Ayashi (Upon the Dust-heap) according to the place upon which it was placed. A mother who thinks this procedure too drastic may call her child Angulu (Vulture) and trust to luck. This dirty bird is said to disgust the spirits, which is somewhat confusing, considering that certain of them, Jato, for instance, is anything but polished, and one bori [spirit] bears this very name. The real explanation seems to be that the spirits do not want the child because of itself, but merely to punish the mother, and if so her best means of keeping it is to convince them that she would be glad if it went. 
Such pragmatic customs necessitate the acceptance of a harsh (and unavoidable) reality - that it is common for children to die young. In antiquity, a newborn could be considered a separate category of being throughout the first week of life, when most at risk of death, and only named after this critical period has passed. For instance, Plutarch asserts that "until it [the umbilical cord] comes off, the child is more like a plant than an animal" (Roman Questions, 288C) and Aristotle that "the majority of deaths in infancy occur before the child is a week old, hence it is customary to name the child at that age, from a belief that it has now a better chance of survival" (History of Animals, 588a8-10). Holding an official naming ceremony some time after birth is arguably a reflection of this old truth: for instance, the Islamic Aqiqah and Japanese oshichiya ceremonies are traditionally performed on the seventh day after birth, the Jewish Brit milah (for males) on the eighth day, and the Hindu Namakarana on the twelfth day (Williams 2016). In a comparative ethnological survey of 186 societies, $40 \%$ held ceremonies within 2 months of birth; the majority waited until the child was older (Barry and Paxson 1971). Until this time, the child would have no 'officially recognised' name (although informal diminutive names may be used, such as the Chinese rǔmíng, or 'milk name' (Fang and Heng 1983)). By extension, the un-named individual's social position is anonymous and their social status minimal - arguably, it is the rite of passage of a formal presentation (naming) ceremony, not just birth alone, that affirms an individual as a member of society.

For children who die shortly after birth, it could never be known who, in the fullness of time, they would be - their names embody their potential, and by extension affirm both their agency and personhood. A previous analysis of American genealogical data identified a strong relationship between the number of un-named infants and infant mortality rates (McCormick 2010), consistent with the notion that a newborn does not necessarily attain personhood (manifest in a name) until they appear likely to survive. This can also be seen in 
the UK birth records: compared to contemporary records, a higher proportion of historic birth records are un-named, registered only with a placeholder entry such as Girl or Daughter (prior to 1850, approximately 1-3\% of all births in a given year were un-named). This is notable as birth registration is a legal requirement, distinct from the traditional rite of passage of a naming ceremony (in the UK Christian tradition, baptism).

We can speculate that in times of high infant mortality, should a child die prior to their naming (thus, prior to full social acceptance), their death may be born with equanimity but not unduly mourned. As mortality is entwined with poverty, this has previously been observed in anthropological surveys of Brazilian favelas: an implicit acceptance of the 'incomplete personhood' of the un-named deceased is not necessarily indifference at their death nor suppression of grief, but a pragmatic survival strategy in a time of high mortality, a means of protecting ones ontological security from debilitating psychological trauma (Scheper-Hughes 1992).

When it is customary to name the living for a dead relative, the deceased individual is invariably elderly - that is, their life as lived was fully realised and not, for the most part, in potentia. In this case, naming a newborn for this person may be readily seen as a commemorative act, one creating a continuing bond between the living and the dead. By contrast, the life as lived for a dead child is one of potential but no realisation. This fact is also reflected in naming customs. Historic responses to infant mortality can be pragmatic, such as by minimising the personhood of the child until it demonstrates viability (delaying name-giving) or, upon acknowledging personhood, to avoid any divine enmity that threatens it (using apotropaic names).

With this in mind, can a bond between the living and the dead be continued if for whatever reason the deceased was not considered to have ever had 'complete' personhood? If the deceased does not, then re-using the name of a newborn could be interpreted not necessarily 
as a commemorative act (that is, one ensuring the symbolic presence of the recognised dead), but perhaps instead as symbolic reincarnation - that after the premature death of the first child, who survived to term but not perhaps 'full personhood', the second birth could be considered in essence the same individual. By re-using the name, the social identity intended for the first child may be subsumed into, and actualised by, the second. Assuming names embody, and are synonymous with, identity, then in this respect, the re-use of a full name could be seen as a transcendence of death - in the social sense of death (Králová 2015). The intricate relationship of name and identity underpin these interpretations of this naming practice, of name re-use either as a commemorative act (to maintain a continuing bond with the dead) or a pragmatic one (where names can be given to another as they are disassociated from those who died before social acceptance). It is also necessary to consider how death was conceptualised in this period. Analyses of euphemistic metaphors in Victorian obituaries (Crespo-Fernández 2006) and epitaphs (Crespo-Fernández 2013) suggest there was, in general, a positive value-judgement on human mortality - that death was commonly conceptualized as a desirable event, set against an influential backdrop of Christian beliefs in resurrection and eternal life.

It is a triumph of medicine and public health infrastructure that further data is unavailable - in the UK, the custom of re-using names is a historical remnant, one largely absent from contemporary records. Nevertheless, the rise and fall of this custom over time reflects a more universal point - that the beginning of life has both a social and biological dimension, as also true of the end.

\section{Disclosure statement}

The author declares that there are no competing interests. 


\section{References}

Alia, Valerie. 2009. Names and Nunavut: Culture and Identity in the Inuit Homeland. 1 ed: Berghahn Books.

Atkins, P.J. 1999. "Milk consumption and tuberculosis in Britain, 1850-1950." In Order and disorder : the health implications of eating and drinking in the nineteenth and twentieth centuries., edited by A. Fenton, 83-95. Tuckwell Press.

Barry, Herbert, and Leonora M. Paxson. 1971. "Infancy and Early Childhood: Cross-Cultural Codes 2." Ethnology 10 (4):466-508. doi: 10.2307/3773177.

Bell, Frances, and Robert Millward. 1998. "Public health expenditures and mortality in England and Wales, 1870-1914." Continuity and Change 13 (2):221-249. doi: undefined.

Bush, Stephen J., A. Powell-Smith, and T.C. Freeman. 2018. "Network analysis of the social and demographic influences on name choice within the UK (1838-2016)." https://doi.org/10.31235/osf.io/bzumt.

Crespo-Fernández, Eliecer. 2006. "The Language of Death: Euphemism and Conceptual Metaphorization in Victorian Obituaries." SKY Journal of Linguistics 19:101-130.

Crespo-Fernández, Eliecer. 2013. "Euphemistic Metaphors in English and Spanish Epitaphs: A Comparative Study / Metáforas Eufemísticas En Epitafios Ingleses y Españoles: Un Estudio Contrastivo." Atlantis 35 (2):99-118.

Dasen, Véronique. 2011. "Childbirth and Infancy in Greek and Roman Antiquity." In $A$ Companion to Families in the Greek and Roman Worlds, edited by Beryl Rawson.

Dirbas, Hekmat. 2017. "Thy name is deer. Animal names in Semitic onomastics and namegiving traditions: evidence from Akkadian, Northwest Semitic and Arabic." PhD, Humanities, Leiden University.

Fang, Hanquan, and J. H. Heng. 1983. "Social changes and changing address norms in China." Language in Society 12 (4):495-507. doi: 10.1017/s0047404500010216.

Foster, Terrah L, Mary Jo Gilmer, Betty Davies, Mary S Dietrich, Maru Barrera, Diane L Fairclough, Kathryn Vannatta, and Cynthia A Gerhardt. 2011. "Comparison of continuing bonds reported by parents and siblings after a child's death from cancer." Death studies 35 (5):420-440.

Guemple, D. L. 1965. "Saunik: Name Sharing as a Factor Governing Eskimo Kinship Terms." Ethnology 4 (3):323-335. doi: 10.2307/3772991.

Irwin, Melissa D. 2015. "Mourning 2.0 - Continuing Bonds Between the Living and the Dead on Facebook." OMEGA - Journal of Death and Dying 72 (2):119-150. doi: 10.1177/0030222815574830.

Jonsson, Annika. 2015. "Post-mortem social death - exploring the absence of the deceased." Contemporary Social Science 10 (3):284-295. doi: 10.1080/21582041.2015.1078117.

Klass, Dennis. 1993. "Solace and immortality: Bereaved parents' continuing bond with their children." Death Studies 17 (4):343-368.

Králová, Jana. 2015. "What is social death?" Contemporary Social Science 10 (3):235-248. doi: 10.1080/21582041.2015.1114407.

Lee, K. S. 2007. "Infant mortality decline in the late 19th and early 20th centuries: the role of market milk." Perspect Biol Med 50 (4):585-602. doi: 10.1353/pbm.2007.0051. 
Lieberson, Stanley, Susan Dumais, and Shyon Baumann. 2000. "The Instability of Androgynous Names: The Symbolic Maintenance of Gender Boundaries." American Journal of Sociology 105 (5):1249-1287.

Macdonald, Charles. 2009. "Inuit personal names. A unique system?" In Orality in the 21st century: Inuit discourse and practices. Proceedings of the 15th Inuit Studies Conference., edited by B. Collignon and M. Therrien. Paris: INALCO.

McCormick, Albert E. 2010. "Infant Mortality and Child-Naming: A Genealogical Exploration of American Trends." The Journal of Public and Professional Sociology $3(1): 2$.

McCormick, Lisa. 2015. "The agency of dead musicians." Contemporary Social Science 10 (3):323-335. doi: 10.1080/21582041.2015.1114664.

Mendels, D. 2007. On Memory: An Interdisciplinary Approach: Peter Lang.

Mitterauer, M. 1993. Ahnen und Heilige: Namengebung in der europäischen Geschichte. München: Beck.

Nickman, Steven L. 1996. "Continuing bonds: New understandings of grief." About the Book. Dennis Klass, Phyllis R. Silverman, and Steven Nickman (Eds.). Philadelphia: Taylor and Francis.

Ogden, Charles Kay, and Ivor Armstrong Richards. 1946. The meaning of meaning: Harvest Book.

Okehie-Offoha, Marcellina Ulunma, and Matthew N. O. Sadiku. 1995. Ethnic and cultural diversity in Nigeria. Trenton, N.J.: Africa World Press.

Root, Briana L., and Julie Juola Exline. 2014. "The Role of Continuing Bonds in Coping With Grief: Overview and Future Directions." Death Studies 38 (1):1-8. doi: $10.1080 / 07481187.2012 .712608$.

Samuel, Edgar R. 1969. "New light on the Selection of Jewish Children's Names." Transactions \& Miscellanies (Jewish Historical Society of England) 23:64-86.

Scheper-Hughes, Nancy. 1992. Death Without Weeping: The Violence of Everyday Life in Brazil. Berkley: University of California Press.

Seeman, Mary V. 1983. "The Unconscious Meaning of Personal Names." Names 31 (4):237244. doi: 10.1179/nam.1983.31.4.237.

Stroebe, Margaret, and Henk Schut. 2005. "To Continue or Relinquish Bonds: A Review of Consequences for the Bereaved." Death Studies 29 (6):477-494. doi: 10.1080/07481180590962659.

Toplean, Adela. 2015. "To resist or to embrace social death? Photographs of couples on Romanian gravestones." Contemporary Social Science 10 (3):296-309. doi: 10.1080/21582041.2015.1106759.

Tremearne, A. J. N. 1914. The Ban of the Bori: Demons and Demon-Dancing in West and North Africa. London: Routledge.

Tremearne, Major AJN. 2014. Hausa superstitions and customs: an introduction to the folklore and the folk: Routledge.

Vickio, Craig J. 1999. "Together in spirit: keeping our relationships alive when loved ones die." Death Studies 23 (2):161-175. doi: 10.1080/074811899201127.

West, Jevin D., Jennifer Jacquet, Molly M. King, Shelley J. Correll, and Carl T. Bergstrom. 2013. "The Role of Gender in Scholarly Authorship." PLoS ONE 8 (7):e66212. doi: 10.1371/journal.pone.0066212.

Williams, Victoria. 2016. Celebrating Life Customs around the World: From Baby Showers to Funerals. Westport, Connecticut, USA: Greenwood Press. 


\section{Notes on contributor}

Stephen J. Bush has a $\mathrm{PhD}$ in evolutionary genomics from the University of Bath, was a postdoctoral research fellow at the Roslin Institute, University of Edinburgh, and is currently a bioinformatician at the University of Oxford.

Correspondence to: Stephen J. Bush, Nuffield Department of Clinical Medicine, University of Oxford, John Radcliffe Hospital, Headington, Oxford, OX3 9DU. E-mail: stephen.bush@ndm.ox.ac.uk

\section{Tables}

Table 1. Number of death records associated with subsequent sibling births, and the proportion of which that re-use the name, in part or in full.

\begin{tabular}{|l|l|l|}
\hline Type of record & Number of records & Percentage of total records \\
\hline $\begin{array}{l}\text { Deaths associated with } \\
\text { subsequent sibling births }\end{array}$ & 9452 & - \\
\hline $\begin{array}{l}\text { Births with the same full name as } \\
\text { the deceased }\end{array}$ & 947 & 10.0 \\
\hline $\begin{array}{l}\text { Births with the same first name as } \\
\text { the deceased }\end{array}$ & 1975 & 20.9 \\
\hline $\begin{array}{l}\text { Births which use the first name of } \\
\text { the deceased as a middle name }\end{array}$ & 403 & 4.3 \\
\hline $\begin{array}{l}\text { Births which use the middle name } \\
\text { of the deceased as a middle name }\end{array}$ & 2369 & 25.1 \\
\hline
\end{tabular}




\section{Figures}
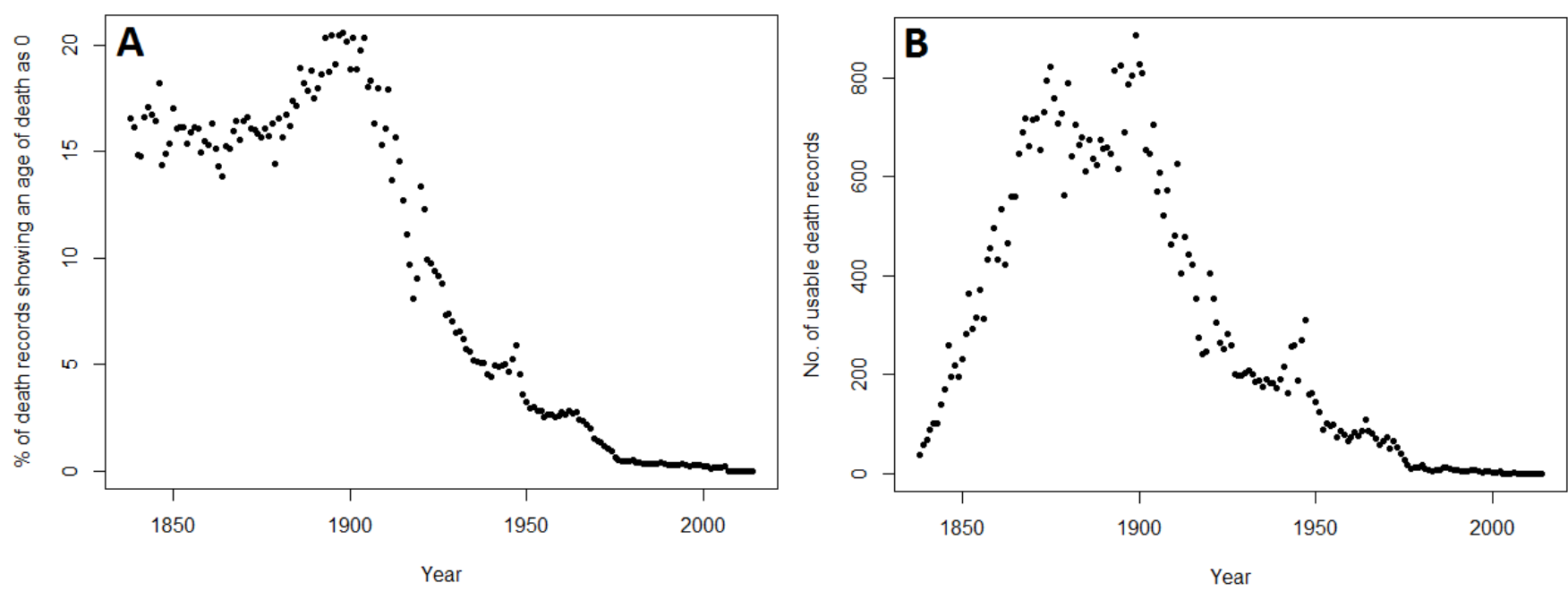

Figure 1. Proportion of the total recorded deaths per year at $<1$ year of age (A) and the number of usable death records obtained per year (B). Usable death records are those which can be successfully cross-referenced between the birth, marriage and death registers in order to make a reasonable prediction of family relationships, with each usable death record associated with the birth record of one or more siblings. The initial dearth of usable records is a consequence of the conservative filter criteria employed - a middle name was required on each record, although these were not widely used during this period. 